\title{
Discrimination of biomass burning smoke and clouds in MAIAC algorithm
}

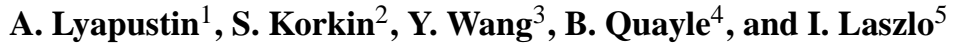 \\ ${ }^{1}$ Laboratory for Atmospheres, NASA Goddard Space Flight Center, Greenbelt, Maryland, USA \\ ${ }^{2}$ Universities Space Research Association, Columbia, Maryland, USA \\ ${ }^{3}$ University of Maryland Baltimore County, Baltimore, Maryland, USA \\ ${ }^{4}$ USDA Forest Service, Salt Lake City, Utah, USA \\ ${ }^{5}$ NOAA/NESDIS/STAR, Camp Springs, Maryland, USA
}

Correspondence to: A. Lyapustin (alexei.i.lyapustin@nasa.gov)

Received: 9 June 2012 - Published in Atmos. Chem. Phys. Discuss.: 31 July 2012

Revised: 26 September 2012 - Accepted: 2 October 2012 - Published: 24 October 2012

\begin{abstract}
The Multi-Angle Implementation of Atmospheric Correction (MAIAC) algorithm makes aerosol retrievals from MODIS data at $1 \mathrm{~km}$ resolution providing information about the fine scale aerosol variability. This information is required in different applications such as urban air quality analysis, aerosol source identification etc. The quality of high resolution aerosol data is directly linked to the quality of cloud mask, in particular detection of small (sub-pixel) and low clouds. This work continues research in this direction, describing a technique to detect small clouds and introducing the "smoke test" to discriminate the biomass burning smoke from the clouds. The smoke test relies on a relative increase of aerosol absorption at MODIS wavelength $0.412 \mu \mathrm{m}$ as compared to $0.47-0.67 \mu \mathrm{m}$ due to multiple scattering and enhanced absorption by organic carbon released during combustion. This general principle has been successfully used in the OMI detection of absorbing aerosols based on UV measurements. This paper provides the algorithm detail and illustrates its performance on two examples of wildfires in US Pacific North-West and in Georgia/Florida of 2007.
\end{abstract}

\section{Introduction}

The Multi-Angle Implementation of Atmospheric Correction (MAIAC) is a new MODIS algorithm which retrieves aerosol information over land simultaneously with parameters of the bidirectional reflectance distribution function (BRDF) model (Lyapustin et al., 2011a,b; 2012a). MAIAC uses the time se- ries (TMS) analysis and processing of groups of pixels which allows to impose physical constraints on the time-space variability of aerosols and surface reflectance captured with the MODIS daily global coverage: namely, aerosols vary slowly in space but may change between consecutive MODIS observations, whereas the land surface reflectance has a high spatial variability but low rate of change at short time intervals (see also Dubovik et al., 2011; Govaerts et al., 2010). MAIAC features an independent cloud mask algorithm which uses TMS analysis to identify clear conditions based on stable spatial pattern from surface over time as opposed to generally random pattern created by clouds (Lyapustin et al., 2008).

A distinctive feature of MAIAC is the high $1 \mathrm{~km}$ resolution of the aerosol product. While high resolution is in great demand for urban air quality analysis and other applications, it also raises the standards for the accuracy of cloud detection. The recent paper of Lyapustin et al. (2012b) explored ways to reduce cloud contamination in MAIAC aerosol retrievals. Specifically, we used analysis of spectral residuals between the measured and computed (based on retrieved parameters) top of atmosphere (TOA) reflectances to identify additional clouds. We have also adapted the histogram filtering approach of the current MODIS operational "Dark Target" algorithm MOD04 (Levy et al., 2007) which screens data below the 20th and above the 50th percentiles in a $10 \mathrm{~km}$ window as probably contaminated by shadows and clouds, respectively. In MAIAC, similar filtering approach was applied to $1 \mathrm{~km}$ AOT retrievals in the $25 \mathrm{~km}$ window with the 
dynamic upper threshold being a function of the cloud fraction. A limited testing showed a dramatic improvement in the aerosol product quality without big impact on retrievals with spatially variable aerosols.

A subsequent large scale analyses of MODIS data, however, revealed a more complex picture. First, it showed that the introduced "spectral residual" test is redundant and can be omitted in favor of a more universal and generic "histogram" test. Second, regardless of specific implementation, the histogram test was found to filter retrievals with high AOT gradient which often present a particular interest for analysis. In the end, this is not a surprise given that the histogram test implies a certain level of spatial homogeneity of aerosol in the atmosphere, and its success in filtering clouds directly translates into its failure to preserve AOT data with high spatial variability. In general, high AOT gradients at a scale of several kilometers and less are generated by two main types of aerosol emission near its sources, namely fire smoke, usually associated with biomass burning, and dust storms. This further work highlighted the need for developing "smoke" and "dust" tests to help protect aerosol data with strong heterogeneity from being filtered out. The current paper presents further development of algorithm MAIAC: it describes the new small cloud filter in Section 2 and the "smoke" test in Sect. 3. Section 4 provides an illustration of achieved data processing quality with two examples of wildfires in US Pacific North-West and in Georgia/Florida of 2007.

\section{Detection of small clouds}

The MAIAC cloud mask (CM) algorithm was described earlier (Lyapustin et al., 2008). In brief, the CM algorithm is based on the notion that the spatial pattern of a given scene is stable and reproducible for short time periods under cloud-free conditions, whereas clouds randomly disturb this pattern. The algorithm uses covariance analysis to identify cloud-free regions. On this basis, it builds a reference clear-sky image of the surface, which is used for pixel-level cloud masking. The reference image is updated each time clear conditions are detected, and thus it dynamically adapts to changing state of the land surface. The algorithm has an internal land-water-snow dynamic classification, which detects surface changes and guides MAIAC processing.

The reference clear-sky TOA reflectance, available for every $1 \mathrm{~km}$ pixel, significantly increases confidence of detecting both cloudy and clear pixels. This gives a particular advantage in difficult conditions, e.g. in tropical regions of Amazonia characterized by high cloudiness especially during the wet season (Hilker et al., 2012). Also as a consequence, MAIAC does not use "probably clear" and "probably cloud" categories which are common to the operational cloud mask algorithms.
In general, it is easy to identify large, bright and cold clouds and difficult to detect the low and small (sub-pixel) clouds as they do not display sufficient brightness temperature or reflectance contrast. At the same time, small cumulus clouds may have a large effect on the retrieval statistics of regions defined as cloudy and clear sky, creating bias in aerosol radiative forcing (Koren et al., 2008). In the MAIAC $\mathrm{CM}$ algorithm, the problem of small clouds may be exacerbated by the use of $1 \mathrm{~km}$ gridded data obtained from the original MODIS 500m measurements (nadir resolution). The $1 \mathrm{~km}$ gridding is required for the time series analysis used in both aerosol retrieval and atmospheric correction algorithms of MAIAC as well as in CM. However, it obviously reduces the reflectance contrasts which otherwise could be found in the original $500 \mathrm{~m}$ data. As an example, Fig. 1a illustrates the difference between the $1 \mathrm{~km}$ and $500 \mathrm{~m}$ grid resolution in the RGB MODIS Aqua image for the $150 \times 150 \mathrm{~km}^{2}$ area in Georgia, USA, the latter showing significantly more contrast and fine level detail. The arrow points at a small cloud which is still observable at $500 \mathrm{~m}$ resolution but becomes indistinguishable at $1 \mathrm{~km}$. This discussion highlights the idea of using the $500 \mathrm{~m}$ resolution data to improve cloud masking (e.g., Martins et al., 2002).

After trial and error, we implemented an approach based on the standard deviation of four $500 \mathrm{~m}$ gridded pixels nested in each $1 \mathrm{~km}$ grid cell. Similarly to the reference clear sky image, the standard deviation image $\left(\sigma_{i j}\right)$ is created for the clear conditions and stored in the Queue memory (q. $\sigma$ ) for each $1 \mathrm{~km}$ pixel. The q. $\sigma$-image is dynamically updated with the latest data thus adapting to changing surface conditions over time. Using a pixel-specific value has a strong advantage over the use of generic global thresholds as it automatically accounts for the surface heterogeneity helping cloud detection.

A specific $\sigma$-test is implemented for each $1 \mathrm{~km}$ pixel as follows:

If $\sigma_{i j} \sqrt{\mu}>q \cdot \sigma_{i j}+$ Thresh $\rightarrow$ Cloud.

Here, the multiplier $\sqrt{\mu}$, where $\mu$ is a cosine of view zenith angle, approximately takes into account the pixel growth with scan angle, higher overlap between scan lines, and the resulting reduction of contrast. The term Thresh is a threshold value in the $\sigma$-test. It depends on surface variability, and is obtained as a function of the maximal contrast over a given pixel and its nearest neighbors $\left(\sigma^{\max }\right)$ :

Thresh $=0.005+0.66^{*}\left(\sigma^{\max }-0.005\right)$, and $0.005 \leq$ Thresh $\leq 0.015$.

This approach mitigates the effect of the MODIS pixel growth with the scan angle which becomes important over heterogeneous regions, and helps avoid the impact of high contrast borderlines such as seashore.

Figure 1 gives examples of the MAIAC cloud mask performance for selected days in June and August of 2003, characterized by complex cloudy conditions with large number 


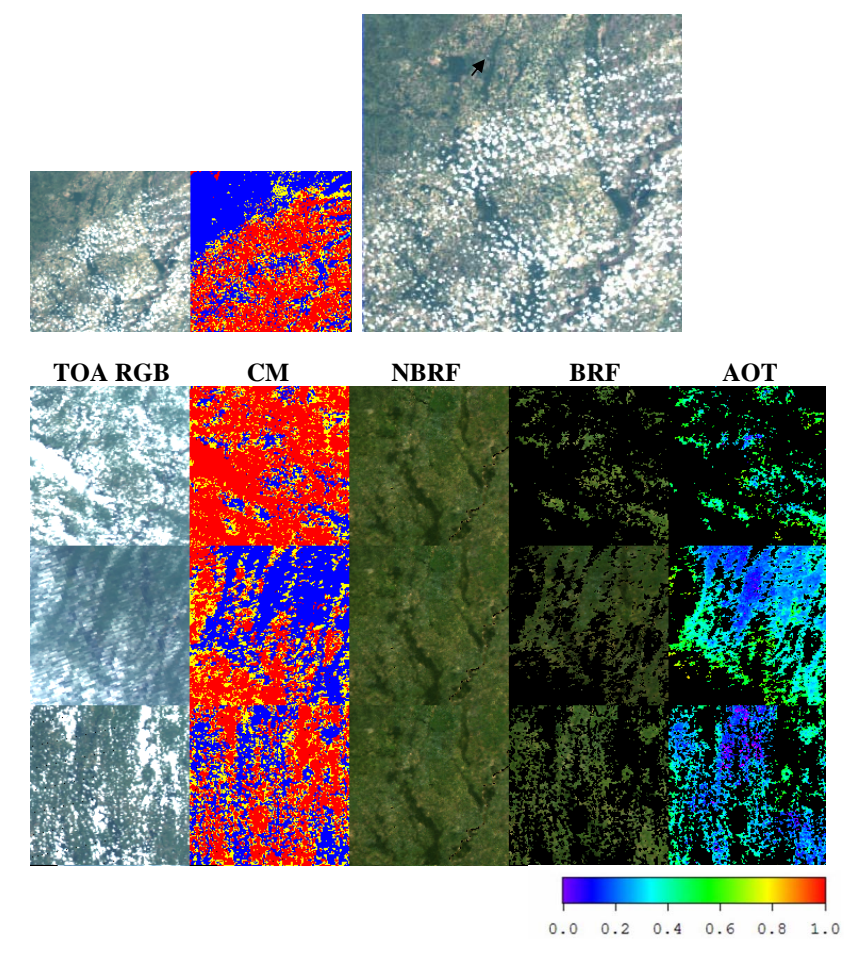

Fig. 1. Top: Effect of spatial resolution on detection of small clouds. The left and right images show the MODIS Aqua RGB image of the $150 \times 150 \mathrm{~km}^{2}$ area in Georgia, USA, for June 29, 2003 at gridded resolution of $1 \mathrm{~km}$ and $500 \mathrm{~m}$, respectively. The MAIAC cloud mask $(\mathrm{CM})$ is shown in the middle with the following legend: Blue - Clear, Red/Yellow - Cloud. Bottom: Illustration of MAIAC performance for the same area in 5-7 August 2003. The five columns show the MODIS Aqua TOA data and MAIAC products including cloud mask, RGB NBRF (bidirectional reflectance computed from the BRDF model for a fixed view geometry of nadir view and $45^{\circ}$ solar zenith angle), BRF (or surface reflectance) and aerosol optical thickness $\left(\mathrm{AOT}_{0.47}\right)$ with scale shown below.

of small clouds. The bottom panel shows additional MAIAC products including the RGB bidirectional reflectance factors (BRF), commonly called surface reflectance, and AOT images which allow a more complex evaluation of the total algorithm performance including cloud mask. The lack of obvious cloud-related artifacts in the BRF and AOT data indicates a good quality of cloud detection.

\section{Smoke test}

\subsection{Absorption and size parameters}

The biomass burning aerosols contain carbonaceous compounds such as black carbon (BC) and organic carbon (OC) which are efficient absorbers of light in the atmosphere. While the BC absorption, e.g. imaginary part of refractive index, is known to be spectrally neutral, different studies indicate that the $\mathrm{OC}$ absorption increases at short wavelengths, namely in the Blue - UV spectral region (e.g., Kirchstetter et al., 2004; Bergstrom et al., 2007; Russell et al., 2010; Jethva and Torres, 2011). The UV wavelengths have been successfully used in the OMI Aerosol Index (AI) algorithm to detect absorbing aerosols (smoke, mineral dust, volcanic ash) and discriminate them from clouds and from weakly absorbing aerosols such as sea salt, sulphates etc. (e.g., Torres et al., 1998; 2007). This detection relies on the fact that adding absorbing aerosols in atmosphere changes spectral contrast of TOA radiance as compared to that from the purely Rayleigh atmosphere. At short wavelengths, the number of scattering events is considerable due to high Rayleigh and aerosol optical thickness, with energy absorbed in each interaction with aerosol particle, which ultimately reduces the reflected radiance. In the case of smoke, an additional absorption may be caused by an enhanced UV light absorption by OC.

In this work, we are using a similar principle based on the MODIS Red, Blue and Deep Blue (DB) bands B1 $(0.646 \mu \mathrm{m}), \mathrm{B} 3(0.466 \mu \mathrm{m})$ and B8 $(0.412 \mu \mathrm{m})$. The developed test (1) isolates aerosol reflectance, and (2) compares the measured reflectance at shortest wavelength $(0.412 \mu \mathrm{m})$ with that predicted from the Red-Blue region. Specifically, an aerosol reflectance is first computed in the Red, Blue and DB channels by subtracting the Rayleigh (path) reflectance and the full surface-reflected signal at TOA from the measurement:

$R_{\lambda}^{\text {Aer }}=R_{\lambda}^{\text {Meas }}-R_{\lambda}^{\text {Molec }}-R_{\lambda}^{\text {Surf }}\left(\tau^{\mathrm{a}}\right)$.

The last term is evaluated using AOT $\left(\tau^{\mathrm{a}}\right)$ initially retrieved with the background aerosol model and spectral surface BRDF known from the previous MAIAC retrievals. The so defined aerosol reflectance represents the atmospheric aerosol backscattering (path reflectance) and aerosolmolecular interactions. Next, we assume that the aerosol reflectance has a power law spectral dependence typical of the optical thickness,

$R_{\lambda}^{\text {Aer }} \sim \lambda^{-b}$.

While Eq. (2) is only an approximation because of the multiple scattering, aerosol-molecular interactions, and spectral dependence of both single scattering albedo and aerosol phase function, it is quite adequate for our purpose. With this assumption, the equivalent Angstrom exponent $b$ is computed next using the Red and Blue channels. Finally, using parameter $b$, we compute predicted aerosol reflectance at $0.412 \mu \mathrm{m}$, and compare it with the measured aerosol reflectance via the absorption parameter (AP):

$\mathrm{AP}=R_{0.412}^{\text {Aer,Meas }} / R_{0.412}^{\text {Aer,Pred }}$, where $R_{0.412}^{\text {Aer,Pred }}=R_{0.466}^{\text {Aer }}\left(\frac{0.466}{0.412}\right)^{b}$.

This test is implemented after the aerosol retrieval with the background aerosol model and before the cloud filter. Despite the different implementation, the idea behind this spectral test is similar to the one behind the OMI aerosol index: to the first order approximation, the clouds, which have 
spectrally neutral behavior, or non-absorbing aerosols, would give the AP values close to unity, whereas the absorbing aerosols would result in the lower AP values. The reduction of AP for absorbing aerosols is expected because of the additional multiple scattering and, in case of smoke, additional OC absorption at $0.412 \mu \mathrm{m}$ as compared to the RedBlue spectral region.

\subsection{Theoretical simulations}

To understand the capability and sensitivity of the proposed test, we conducted a theoretical analysis of smoke-cloud separability based on the introduced absorption parameter. The liquid water cloud was modeled using a lognormal size distribution with radius $5 \mu \mathrm{m}$ and standard deviation $0.5 \mu \mathrm{m}$ using refractive index of Hale and Querry (1973). It is worth noting that since clouds practically do not absorb solar radiation in the blue-red spectrum, the exact properties of clouds do not matter, and the selected cloud model will provide generally representative results. To model the biomass burning aerosol, we selected the value of Absorption Angstrom Exponent $\mathrm{AAE}=2$ and the imaginary reflective index $n_{i}=0.01$ at $0.466 \mu \mathrm{m}$. While the value $\mathrm{AAE}=2$ is slightly higher than those ( 1.4-1.5) based on several field campaign studies and AERONET data compiled in Russell et al. (2010), it is well within the range of the reported AAE values (up to 3-5) observed in the controlled burning experiments (see Russell et al., 2010 and references therein). For the selected MODIS channels $(0.412,0.466$, and 0.646$)$, this gives $n_{i}=0.0113$, 0.01 and 0.0070 , and the aerosol single scattering albedo SSA $=0.9219,0.9246$ and 0.9245 , respectively. In addition, we have also tested the case with spectrally-neutral imaginary index of 0.01 (more representative of $\mathrm{BC}$ ) which gives SSA $=0.9294,0.9246$, and 0.8981 , respectively.

The results of simulations performed with the radiative transfer code SHARM (Lyapustin and Wang, 2005) are shown in Fig. 2. The top panel (a) shows simulated absorption parameter (AP) and the bottom one (b) shows the size parameter (SP) given by the ratio $\mathrm{SP}=R_{0.646}^{\mathrm{Aer}} / R_{0.466}^{\mathrm{Aer}}$ which is equivalent to parameter $b$. The results are presented as a function of the optical thickness. In each panel, the rows show different solar zenith angles $\left(\mathrm{SZA}=0,45,60^{\circ}\right)$, and columns show different relative azimuths $\left(\varphi=35,90,145^{\circ}\right)$. The range of selected azimuthal angles is typical of MODIS observation geometries. The red and black colors represents different view zenith angles $\mu=1$ and 0.5 , respectively.

Each plot shows results for an optically thick cloud (horizontal thick lines), thin clouds corresponding to a given optical thickness (thin lines) and two aerosol types with $\mathrm{AAE}=2$ (Aerosol $(\lambda)$, circles) and with constant $n_{i}=0.01$ (Aerosol, triangles). As expected, the "size parameter" for clouds is close to unity indicating a near-neutral spectral dependence, whereas the typical aerosol values are in the range of 0.6-0.8 indicating much smaller particle size. The aerosol SP values grow with AOT and atmospheric airmass, nevertheless the aerosol SP is distinguishably lower than the cloud value for the analyzed OT range $0-2$. The top panel (AP) shows a separation of non-absorbing clouds (e.g., horizontal lines for optically thick clouds) and absorbing smoke (circles and triangles), which increases with aerosol optical thickness and airmass. A robust separation is achieved for all view geometries at $\mathrm{AOT}_{0.47}>0.5$. At smaller AOT, especially with low SZA and VZA, this test becomes less reliable due to additional uncertainties from the knowledge of spectral surface BRDF.

As specific aerosol absorption is a function of many parameters including type of the burning material and smoldering to flaming fraction ratio, we implemented a smoke test based on separation from the "cloud AP" as follows:

IfAP $_{\mathrm{ij}}<\mathrm{AP}_{\text {Cloud }}-0.03 \rightarrow$ Aerosol,

where $\mathrm{AP}_{\text {Cloud }} \cong 0.97-0.06\left(2-\mu-\mu_{0}\right)$ is approximately parameterized in terms of cosines of the view and solar $\left(\mu_{0}\right)$ zenith angles. The size parameter is additionally used in the mineral dust detection, which will be described separately.

It should be mentioned that presented simulations are limited to the pure smoke vs cloud analysis. For more complex cases with the smoke layer above clouds see Jethva et al. (2012) and Torres et al. (2012).

\section{Examples of MODIS processing}

A detailed example illustrating current MAIAC retrieval capability is shown in Fig. 3 for the case of forest wildfires in the US Pacific North-West in 2007. Shown is the area of $150 \mathrm{~km}$ in the Rocky Mountains centered at $45.5^{\circ} \mathrm{N}$, $115.1^{\circ} \mathrm{W}$. Fires started about DOY 193 and lasted for over two months. Figure 3 displays 10 different columns for each of the 10 days shown, including MODIS Aqua RGB top of atmosphere (TOA) data, MAIAC cloud mask, RGB NBRF (theoretically computed Normalized BRDF for a fixed geometry of nadir view and $\mathrm{SZA}=45^{\circ}$ which can be considered as a background surface image) and BRF (bidirectional reflectance factor often called surface reflectance), $\mathrm{AOT}_{0.47}$, absorption parameter (AP), brightness temperature (BT), reflectance in MODIS cirrus channel $(1.38 \mu \mathrm{m})$, and measured and predicted, based on BRDF model, reflectance in band 7 $(2.1 \mu \mathrm{m})$.

The top three images (DOY 194, 199, 212) show initial fires of relatively low intensity in different conditions. Areas of enhanced smoke absorption are clearly identifiable by low values of the absorption parameter (AP), in contrast to high AP values from clouds or the background aerosol. The last four columns are shown to help discriminate clouds from smoke. For example, usually higher and colder clouds have lower brightness temperature and higher reflectance in the cirrus channel $1.38 \mu \mathrm{m}$ as compared to a clear land or a nearground smoke. The MODIS narrow cirrus channel (band 26) is located in the water vapor band with strong absorption 

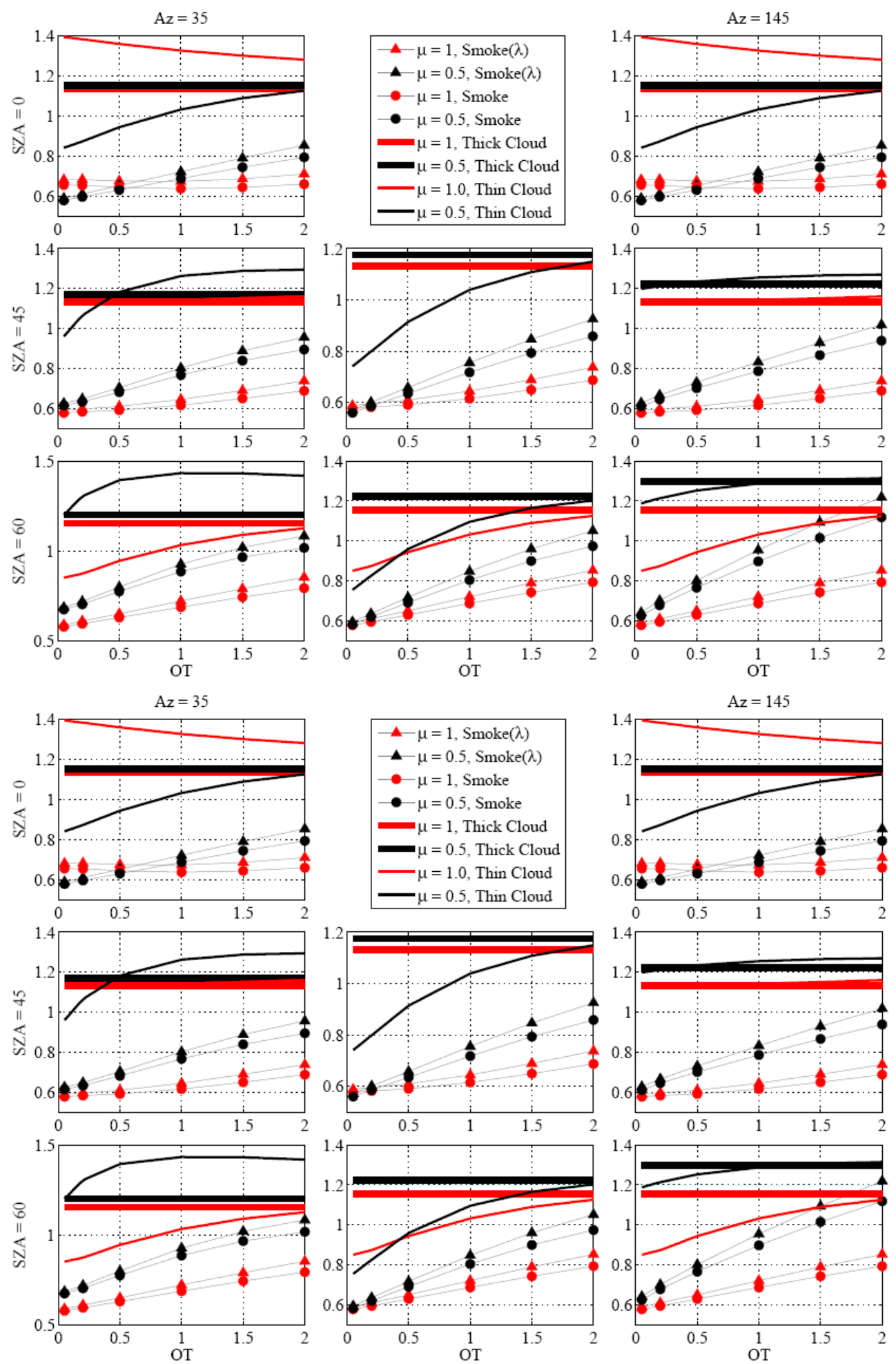

Fig. 2. Simulated Absorption Parameter (top) and Size Parameter (bottom) for different view geometries and optical thickness (OT) for absorbing aerosols (symbols) and clouds (lines). The rows show different solar zenith angles $\left(\mathrm{SZA}=0,45,60^{\circ}\right.$ ), and columns show different relative azimuths $\left(\varphi=35,90,145^{\circ}\right)$. The red and black color represents different view zenith angles $(\mu=1$ and 0.5 , respectively). The thick and thin lines show results for thick and thin (with given OT) clouds, respectively. The circles and triangles indicate aerosols with AAE 2 (Aerosol $(\lambda)$ ) and spectrally independent imaginary refractive index (Aerosol), respectively. The parameters of simulations are provided in the text. 


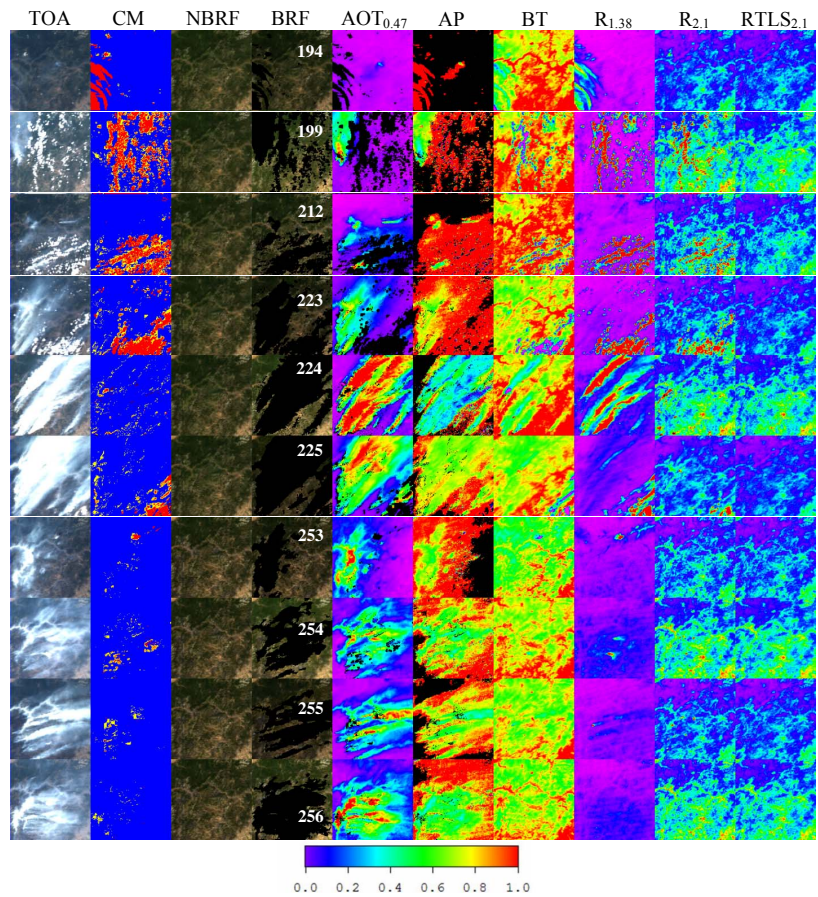

Fig. 3. Illustration of MAIAC algorithm performance for case of forest wildfires in Pacific Northwest, Rocky Mountains, USA, 2007. The images show MODIS Aqua RGB TOA data, MAIAC cloud mask (CM), RGB NBRF and BRF, $\mathrm{AOT}_{0.47}$, absorption parameter (AP), brightness temperature (BT), reflectance in MODIS cirrus channel $(1.38 \mu \mathrm{m})$, and measured and predicted, using retrieved BRDF model, reflectance in B7 $(2.1 \mu \mathrm{m})$. The results are shown for $150 \mathrm{~km}$ tiles for days of year from 194 to 256, as indicated in the 4th column. The blue color of the cloud mask corresponds to clear pixels, and red-yellow show detected clouds. The following scales were used for columns 5-10 (based on displayed rainbow palette): 0-3 (AOT 0.47 ), 0.7-0.91 (AP), 273-305 (BT), 0-0.035 ( $\left.\mathrm{R}_{1.38}\right), 0$ $0.3\left(\mathrm{R}_{2.1}\right.$ and $\left.\mathrm{RTLS}_{2.1}\right)$.

such that a small amount of column water vapor $(0.3-0.5 \mathrm{~cm})$ is usually sufficient to absorb most of radiation reflected by the surface and aerosols into space. Usually, this channel is very dark measuring a low signal, however it becomes bright when the scattering layer (aerosol or cloud) raises above the bulk of column water vapor. These effects are clearly visible in the top three rows of images. The first day (194) shows a sub-visible thin cirrus with low optical depth detected based on lower BT and higher $\mathrm{R}_{1.38}$ as compared to the cloud-free background.

The last two columns show the measured MODIS reflectance at $2.1 \mu \mathrm{m}$ and predicted reflectance based on surface BRDF model retrieved by MAIAC. One can see that in the absence of optically thick clouds the two fields $\left(\mathrm{R}_{2.1}\right.$ and RTLS $_{2.1}$ ) are spatially well correlated (e.g., DOY 194). The correlation at $2.1 \mu \mathrm{m}$ usually remains robust even in conditions of thick smoke plumes. The biomass burning smoke is mostly represented by the fine mode particles and thus has

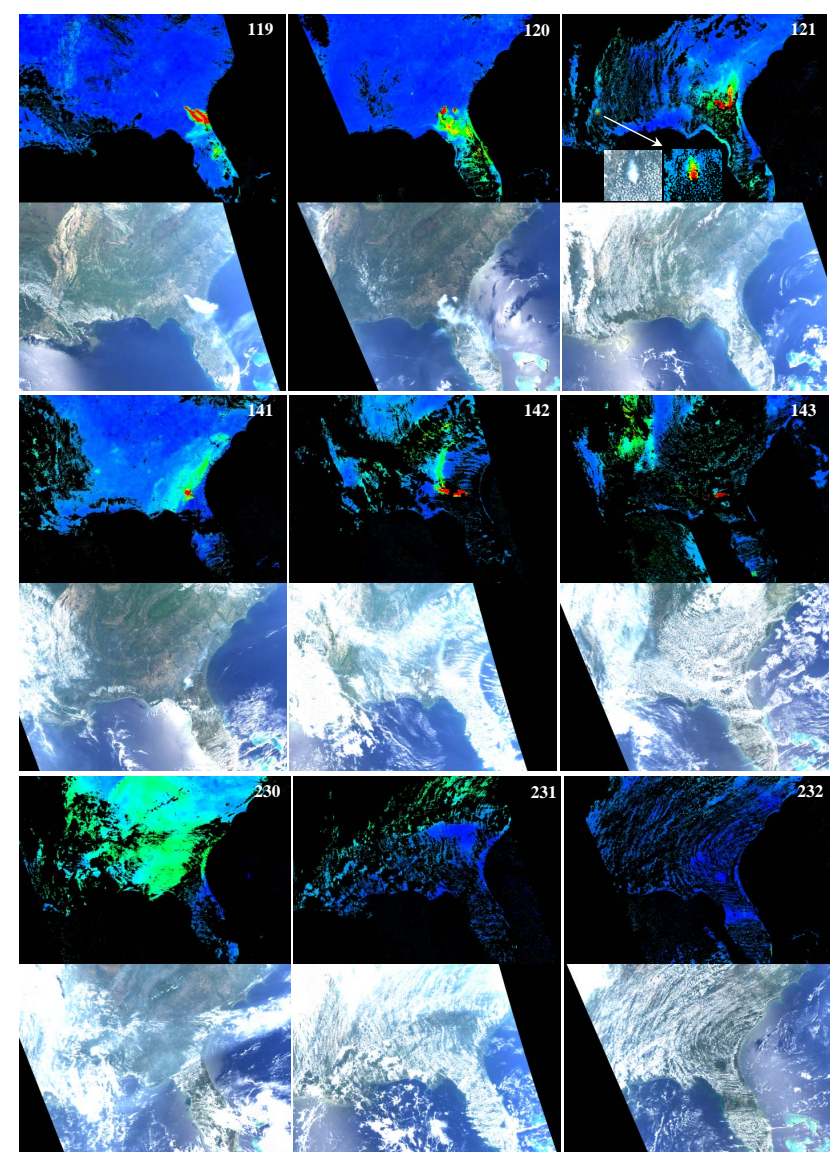

Fig. 4. Examples of MAIAC large-scale aerosol retrievals for the south-eastern US using MODIS Aqua 2007 data. The numbers show the day of the year. The scale of $\mathrm{AOT}_{0.47}$ is $0-3$. The top two rows of images show triplets of consecutive days for the GeorgiaFlorida fires of 2007. An additional large fire on day 121 in Alabama is magnified in the inset. Days 141-143 illustrate conditions of increasing cloudiness with reliable identification of the fire source and north-western transport of smoke. The last three days (230-232) show a gradual removal of polluted air by the weather system in the northern direction.

little effect on the $2.1 \mu \mathrm{m}$ reflectance (Kaufman et al., 2005; Eck et al., 1999, 2009).

The fire reaches its maximal strength on days 224-225. On day 224 , the $\mathrm{BT}$ and $\mathrm{R}_{1.38}$ fields show that smoke rises well above the boundary layer. Based on the brightness temperature contrast of $25-35^{\circ} \mathrm{C}$, the height of the plume can be roughly evaluated as $4-5 \mathrm{~km}$ above the ground. The AP index shows the lowest values among all days indicating high absorption by carbonaceous (BC and OC) aerosols.

The bottom images show the last four days of the fire, which were followed by the cloudy period and the onset of the cold season. These very interesting images (TOA, $\mathrm{AOT}_{0.47}$, and AP) show that a significant fraction of the smoke is concentrated along the mountain valleys making them visibly very bright. At the same time, the nearby 
elevated areas often have a much better air quality with lower AOT.

These examples show that with the introduction of smoke discrimination, MAIAC no longer filters out fire plumes, including those with the high reflectance and AOT contrast. The cloud mask images show that some excessive filtering (yellow color) may still occur on the plume boundaries, in transitional zones to clear areas with $\mathrm{AOT}_{0.47} \sim 0.3-0.6$, where smoke detection becomes less reliable.

Figure 4 shows several large-scale examples of MAIAC aerosol retrievals for the South-Eastern USA using MODIS Aqua for 2007. The top two rows of images show triplets of consecutive days for the Georgia-Florida fires of 2007, the largest fires in the history of both states. These fires, caused by an extreme drought of 2007, started in the second half of April and raged through the end of June (e.g. Christopher et al., 2009). Images for days 119-121 show several strong fire sources in the two states, and another large fire in Alabama magnified in the inset. Days 141-143 illustrate conditions of increasing cloudiness, and reliable identification of the source and of progressively north-western transport of smoke under high cloudiness (DOY 142-143). Finally, the last three days (230-232) show gradual removal of polluted air by the weather system in the northern direction.

\section{Conclusions}

High resolution aerosol data from space observations offer a unique prospective for different disciplines and operational applications focusing on aerosol sources and their emission power. One important application is detection and characterization of the wildfires that affect global population, and the assessment of the air quality in affected areas. This work described a continued development of the MAIAC algorithm by improving the quality of the $1 \mathrm{~km}$ aerosol product with reliable cloud filtering.

MAIAC combines a specialized cloud masking approach with an aerosol screening technique based on the histogram analysis following the MODIS Dark Target operational algorithm (Levy et al., 2007). The histogram-based aerosol filter is a very robust tool based on an assumption that the spatial variability of aerosols is significantly lower than that from clouds. This assumption works well in most cases except when in close proximity to strong aerosol sources, e.g. fire smoke plumes, resulting in filtering the areas of the real aerosol signal, usually the most interesting for analysis.

In the current work, we have augmented MAIAC cloud mask with the spatial variance analysis to improve detection of small sub-pixel clouds. The variance $\sigma$ is computed for every $1 \mathrm{~km}$ pixel from four original MODIS pixels at $500 \mathrm{~m}$ resolution, and is compared to the dynamically updated clearsky value for the same pixel stored in the memory.

We have also introduced a smoke test based on analysis of measured reflectance in the MODIS Red, Blue and Deep
Blue channels. This test detects absorbing smoke aerosols based on higher absorption at shorter wavelengths, which is a result of multiple scattering and increased absorption by organic carbon released during combustion. Using two examples of forest fires in the US Pacific Northwest and Georgia/Florida in 2007, we show for the first time that robust discrimination of the biomass burning aerosol can be achieved using visible set of wavelengths rather than the UV range, the latter being the mainstream approach with long history of successful operational use.

The developed smoke test fully leverages MAIAC synergistic processing by using available spectral BRDF information. This facilitates reliable smoke detection in relatively clear conditions. It should be mentioned, however, that at high optical depth, sensitivity of TOA radiance to the surface is low, therefore the same approach can be successfully used to detect dense plumes without a priory knowledge of the surface reflectance.

It should be noted that examples of AOT retrievals, presented above, give a low estimate of the optical thickness for smoke regions and should be considered qualitative as current MAIAC results were produced using a single low absorption aerosol model typical of the East Coast USA (Lyapustin et al., 2011b). With the developed smoke discrimination capability, however, the realistic biomass burning aerosol models will be included in MODIS MAIAC retrievals in the near future.

Acknowledgements. The research of A. Lyapustin, Y. Wang and S. Korkin was funded by the NASA Terrestrial Ecology Program (D. Wickland) and in part by the NOAA GOES-R program (M. Goldberg). The work of I. Laszlo is supported by the NOAA GOES-R program.

Edited by: O. Dubovik

\section{References}

Bergstrom, R. W., Pilewskie, P., Russell, P. B., Redemann, J., Bond, T. C., Quinn, P. K., and Sierau, B.: Spectral absorption properties of atmospheric aerosols, Atmos. Chem. Phys., 7, 5937-5943, doi:10.5194/acp-7-5937-2007, 2007.

Christopher, S. A., Gupta, P., Nair, U., Jones, T. A., Kondragunta, S., Wu, Y., Hand, J., and Zhang, X.: Satellite Remote Sensing and Mesoscale Modeling of the 2007 Florida/Georgia Fires, IEEE J. Select. Top. Appl. Earth Obs. Remote Sens., 26, 1-13, 2009.

Dubovik, O., Herman, M., Holdak, A., Lapyonok, T., Tanré, D., Deuzé, J. L., Ducos, F., Sinyuk, A., and Lopatin, A.: Statistically optimized inversion algorithm for enhanced retrieval of aerosol properties from spectral multi-angle polarimetric satellite observations, Atmos. Meas. Tech., 4, 975-1018, doi:10.5194/amt-4975-2011, 2011.

Eck, T. F., Holben, B. N., Reid, J. S., Dubovik, O., Smirnov, A., O'Neill, N. T., Slutsker, I., and Kinne, S.: Wavelength dependence of the optical depth of biomass burning, urban and desert dust aerosols, J. Geophys. Res., 104, 31333-31350, 1999. 
Eck, T. F., Holben, B. N., Reid, J. S., Sinyuk, A., Hyer, E. J., O’Neill, N. T., Shaw, G. E., Vande Castle, J. R., Chapin, F. S., Dubovik, O., Smirnov, A., Vermote, E., Schafer, J. S., Giles, D., Slutsker, I., Sorokine, M., and Newcomb, W. W.: Optical properties of boreal region biomass burning aerosols in central Alaska and seasonal variation of aerosol optical depth at an Arctic coastal site, J. Geophys. Res., 114, D11201, doi:10.1029/2008JD010870, 2009.

Govaerts, Y. M., Wagner, S., Lattanzio, A., and Watts, P.: Joint retrieval of surface reflectance and aerosol optical depth from MSG/SEVIRI observations with an optimal estimation approach: 1. Theory, J. Geophys. Res., 115, D02203, doi:10.1029/2009JD011779, 2010.

Hale, G. M. and Querry, M. R.: Optical constants of water in the 200-nm to $200 \mu \mathrm{m}$ wavelength region, Appl. Optics, 12, 555563, 1973.

Hilker, T., Lyapustin, A. I., Tucker, C. J., Sellers, P. J., Hall, F. G., and Wang, Y.: Remote Sensing of Tropical Ecosystems: Atmospheric Correction and Cloud Masking Matter. Remote Sens. Environ., in press, doi:10.1016/j.rse.2012.08.035, 2012.

Jethva, H. and Torres, O.: Satellite-based evidence of wavelengthdependent aerosol absorption in biomass burning smoke inferred from Ozone Monitoring Instrument, Atmos. Chem. Phys., 11, 10541-10551, doi:10.5194/acp-11-10541-2011, 2011.

Jethva, H., at al.: A color ratio Method for Simultaneous Retrieval of Aerosol and Cloud Optical Thickness of above-cloud absorbing aerosols from passive sensors: Application to MODIS Measurements: TGRS-2012-00652.R1, under review, 2012.

Kaufman, Y. J., Boucher, O., Tanré, D., Chin, M., Remer, L., and Takemura, T.: Aerosol anthropogenic component estimated from satellite data, Geophys. Res. Lett., 32, L17804, doi:10.1029/2005GL023125, 2005.

Koren, I., Oreopoulos, L., Feingold, G., Remer, L. A., and Altaratz, O.: How small is a small cloud?, Atmos. Chem. Phys., 8, 38553864, doi:10.5194/acp-8-3855-2008, 2008.

Levy, R. C., L. Remer, S. Mattoo, E. Vermote, and Y. J. Kaufman: Second-generation algorithm for retrieving aerosol properties over land from MODIS spectral reflectance, J. Geophys. Res., 112, D13211, doi:10.1029/2006JD007811, 2007.

Lyapustin, A.: Radiative Transfer Code SHARM for Atmospheric and Terrestrial Applications, Appl. Optics, 44, 7764-7772, 2005

Lyapustin, A., Wang, Y., and Frey, R.: An Automatic Cloud Mask Algorithm Based on Time Series of MODIS Measurements, J. Geophys. Res., 113, D16207, doi:10.1029/2007JD009641, 2008.
Lyapustin, A., Martonchik, J., Wang, Y., Laszlo, I., and Korkin, S.: Multi-Angle Implementation of Atmospheric Correction (MAIAC): Part 1. Radiative Transfer Basis and Look-Up Tables, J. Geophys. Res., 116, D03210, doi:10.1029/2010JD014985, 2011a.

Lyapustin, A., Wang, Y., Laszlo, I., Kahn, R., Korkin, S., Remer, L., Levy, R., and Reid, J. S.: Multi-Angle Implementation of Atmospheric Correction (MAIAC): Part 2. Aerosol Algorithm, J. Geophys. Res., 116, D03211, doi:10.1029/2010JD014986, $2011 \mathrm{~b}$.

Lyapustin, A., Wang, Y., Laszlo, I., Hilker, T., Hall, F., Sellers, P., Tucker, J., and Korkin, S. : Multi-Angle Implementation of Atmospheric Correction for MODIS (MAIAC). Part 3: Atmospheric Correction, Remote Sens. Environ, in review, 2012a.

Lyapustin, A., Wang, Y., Laszlo, I., and Korkin, S.: Improved cloud screening in MAIAC aerosol retrievals using spectral and spatial analysis, Atmos. Meas. Tech., 5, 843-850, doi:10.5194/amt-5843-2012, 2012 b.

Martins J. V., Tanré, D., Remer, L. A., Kaufman, Y. J., Mattoo, S., and Levy, R.: MODIS cloud screening for remote sensing of aerosol over oceans using spatial variability, Geophys. Res. Lett., 29, 1619, doi:10.1029/2001GL01352, 2002.

Russell, P. B., Bergstrom, R. W., Shinozuka, Y., Clarke, A. D., DeCarlo, P. F., Jimenez, J. L., Livingston, J. M., Redemann, J., Dubovik, O., and Strawa, A.: Absorption Angstrom Exponent in AERONET and related data as an indicator of aerosol composition, Atmos. Chem. Phys., 10, 1155-1169, doi:10.5194/acp-101155-2010, 2010.

Torres, O., Bhartia, P. K., Herman, J. R., Ahmad, Z., and Gleason, J.: Derivation of aerosol properties from satellite measurements of backscattered ultraviolet radiation: Theoretical basis, J. Geophys. Res., 103, 17099-17110, 1998.

Torres, O., Tanskanen, A., Veihelmann, B., Ahn, C., Braak, R., Bhartia, P. K., Veefkind, P., and Levelt, P.: Aerosols and surface UV products from Ozone Monitoring Instrument observations: An overview, J. Geophys. Res., 112, D24S47, doi:10.1029/2007JD008809, 2007.

Torres, O., Jethva, H., and Bhartia, P. K.: Retrieval of aerosol optical depth over clouds from OMI observations: Sensitivity analysis and case studies, J. Atmos. Sci., 69, 1037-1053, doi:10.1175/JAS-D-11-0130.1, 2012. 